\title{
Spatial Inequalities and Wind Farm Development in the Dodecanese Islands-Legislative Framework and Planning: A Review
}

\author{
Maria Panagiotidou ${ }^{1, *}$, George Xydis ${ }^{2,3}$ and Christopher Koroneos ${ }^{1}$ \\ 1 Interdisciplinary Programme of Postgraduate Studies Environment and Development, \\ National Technical University of Athens, Heroon Polytechniou 9, Zografou, Athens 15780, Greece \\ 2 Soft Energy Applications \& Environmental Protection Lab, Piraeus University of Applied Sciences, \\ P.O. Box, 41046, Athens 12201, Greece; gxydis@gmail.com \\ 3 Georgios Xydis, xydis.gr/gx, Perissos, N. Ionia, Athens 14232, Greece; koroneos@chemeng.ntua.gr \\ * Correspondence: mara.pann@gmail.com; Tel.: +30-694-9941-917
}

Academic Editor: Yu-Pin Lin

Received: 6 April 2016; Accepted: 8 July 2016; Published: 16 July 2016

\begin{abstract}
Islands present sustainable energy growth challenges due to a number of reasons such as remoteness, limited energy resources, vulnerability to external events and strong dependence on international trade agreements. In particular, the Dodecanese Islands of the Aegean Sea cover their electricity needs mostly on the basis of autonomous conventional stations, consuming significant quantities of imported oil annually. Renewable energy sources (RES) penetration increase addresses the global requirements towards a carbon neutral environment, and wind farms (WFs) are among the most well-known green electricity-production alternatives. The study explores wind power installation potential of the Dodecanese Islands and the storage or interconnection options, based on the national and European legislative framework and the international scientific literature. The major finding is that, due to the high wind potential of the area, the National policy and targets focus on the installation of great RES power at Greek islands. Hence, private interests, who are willing to carry out the electrical interconnection of islands to the mainland, serve the same objective. Both scientific and business proposals overcome the local wind power installation capacity and neglect local specifics and needs.
\end{abstract}

Keywords: renewable energy; wind power; Dodecanese Islands

\section{Introduction}

Globally, islands occupy $1 / 6$ of the earth's surface and accommodate $10 \%$ of its population [1]. Their special nature has already been detected since 1992 with Rio declarations; hence, their vulnerability makes the pursuit of sustainable policies a tricky task [2]. Over the past decade, the international community was concerned about islands' sustainability as indicated by the World Conference on sustainable development of small islands of the United Nations in 1994 [3], the White Paper on renewable energy sources (RES) of the European Energy Commission [4] and the first European conference on sustainable development of islands, in 1997 [5].

Islands located a rather long distance from the mainland, having little chance to be connected to the mainland grid, use imported diesel or similar fuels, whose price is considerably high, in order to cover their demand. The problems are mainly due to the low energy consumption, transportation, and fuel storage, which increase the overall cost of energy [6]. More specifically, energy production of touristic islands notes high annual seasonality and the installed power plants are proportionally much larger, aiming at covering demand peaks [7]. 
Islands may not have as many natural resources as continental areas have, however, in most cases, sun and wind power are in abundance [8]. This is the main reason why there is extended research lately on RES integration increase in the electrical grid. The requirement to meet the needs of islanders without endangering energy supply and cost-effectiveness, along with the exploitation of the on-site available RES solutions and energy storage, preconceive a more sustainable model for RES integration.

The interconnection-storage dipole has intensely been discussed over the last few decades in order to identify the optimal solution for non-interconnected islands. The debate among planners and independent power producers who show an interest in islands continues and is invigorated when new technological developments arise and new parameters redefine the investments' priorities regarding the solution approach (cabling or local storage). However, sometimes, the selected approach is more a political decision and less a technical one.

The present paper studies RES penetration increase potential in Greek islands, focusing on the Dodecanese Islands. Authors are interested in wind energy production, as wind farms (WFs) are of key importance in the energy industry, having a share of more than $50 \%$ of the renewable energy production, according to the national target "20-20-20", as defined in Law 3851/2010. More specifically, the study is a review of legislation, energy policy and targets, scientific proposals and investors' objectives, regarding WF integration increase in islands. The fact that all these aspects are brought to and discussed on the same table is the main contribution of this work.

The paper continues as follows: Section 2 states the methodology used. Section 3 presents the existing European and National institutional framework and the major issues raised regarding the national policy and targets adopted. The debate for RES integration increase at the electrical network is described in Section 4. The first part discusses scientific proposals for energy planning on islands around the world, while the second part deals with the interconnection potential of Greek islands. Section 5 presents and analyses the case study used: the Dodecanese islands. Finally, conclusion remarks are included in Section 6.

\section{Methodology}

The study is based on two research pillars. The first one is a "decoding" process of the institutional framework for renewable energy and WF installation as well as the analysis of the current scientific proposals on RES integration increase in islands, highlighting all critical issues. The second pillar focuses on the prospect of RES integration increase in the Dodecanese Islands and discusses locally emerging issues. The research relies on literature review of the publicly available literature from academic, government, and private sources. Data analysis material has been retrieved from the Hellenic Electricity Distribution Network Operator S.A. (HEDNO) and the Hellenic Statistical Authority (HSA).

\section{European and National Institutional Framework}

Environmental protection has been a statutory objective of the EU since the Single European Act and it was associated with the economy for the first time in 1987, in the light of "sustainable development". According to Maastricht treaty, signed in 1992, environmental protection, economic development, and competitiveness have a positive association. The Single European Energy Policy [9] sets the promotion of energy efficiency, energy conservation, and the development of RES as its main objectives, while two years later, Directive 2009/28/EC is the first to set binding energy targets for Member States to be fulfilled by 2020, requiring the development of National Action Plans.

In terms of legislation, energy production from RES was introduced in Greece in 1994, by the Law 2244/1994, establishing the licensing process. Under Law 2773/1999, green electricity production has both priority access to network and favourable pricing. Under Directives 2001/77/EC and 2004/8/EC, incorporated in Greek legislative framework by Law 3468/2006, national targets for increased participation of RES in the energy balance of electricity generation had been set but not achieved. It was not until 2008 that the "Special Framework for Spatial Planning and Sustainable 
Development for RES" (RES-SFSPSD) was adopted with a view to giving to policies for RES plant sitting the form of rules and criteria.

Law 3851/2010 "RES development acceleration to address climate change [...]" was established during the economic crisis in Greece, in order to simplify the licensing process and incorporate Directive 2009/28/EC into the Greek law. The latter establishes an overall EU binding target of a 20\% share of RES in energy consumption, setting binding national targets by 2020.

\subsection{Wind Farm Sitting Policies}

The aim of RES sitting policy should be the formulation of a clear framework, using spatial criteria, to facilitate the development of sustainable RES installations, integrated into the natural and human environment, at a local level. The RES-SFSPSD introduced in 2008 withdrew the prohibition of RES installation in forested lands, woodlands, and seashores, a process that had already started in 2001 by Law 2941/2001, and was accelerated in 2012 by the Decision 2499/2012 of the State Council. After all, $95 \%$ of WFs of the mainland are located in forested land [10].

Another RES-SFSPSD contribution to relaxing strict environmental legislation is that "Special Protection Areas" (SPA) of Natura 2000 network can also accommodate RES facilities. Due to the aforementioned reasons, Greece is held accountable in the EU, following the no. 2014/4073 warning letter. In addition, Article 8 of Law 3851/10 amended Law 1650/86 "on the environmental protection" in order to be in accordance with RES-SFSPSD provisions. It is clear that the existing legislative framework gives priority to green investments' attraction rather than sensitive areas' protection. The claim is confirmed by the fact that RES-SFSPSD clearly defines priority areas for WF installation as those of high wind energy potential, without clarifying which are the protected areas to be excluded [11].

As far as islands are concerned, legislation does not distinguish them from the rest of the mainland. The only parameter that changes is the maximum wind turbine density per $\mathrm{km}^{2}$, which is $50 \%$ smaller in comparison with the rest of the country. As for the non-interconnected islands, there is an extra restriction for the installed capacity of wind power stations, which should not exceed twice the peak level of demand, as stipulated in the medium-long term (10 years) plan.

It can be assumed that there are no significant specific provisions for the islands of the country, despite the fact that they display a discernible profile for the landscape (extended coastline and protected species), the natural resources, the activities taking place (tourism), and the annual energy needs (seasonal demand), which will be analysed in the following sections.

\subsection{The National Target for RES}

According to the National Action Plan, wind power is expected to produce more than $50 \%$ of the total green energy, highlighting the growing criticality of WF installation issues. The total power of RES mixture will reach $15 \mathrm{GW}$ in 2020 and more than $7 \mathrm{GW}$ of them should be installed in the next five years. The new RES power requires high installation rates, which will exceed the average of $1.000 \mathrm{MW} /$ year, including a broad construction program of new transmission lines and substations, pumping stations, and flexible thermal gas plants [12]. The state bears the construction cost of all infrastructure required.

It can be assumed that the national policy on RES is clearly oriented towards the development of large scale renewables which could be characterised as projects of dubious environmental compatibility [13]. Despite the fact that there can be no refusal of large-scale RES construction, the unilateral commitment to high power applications alters the spirit of renewable energy technology, challenging social reactions by maintaining the misconception that rural regions must bear the weight of feeding urban areas with natural resources without obtaining equivalent benefits [14]. Additionally, a significant failure of the institutional framework is that it doesn't include actual energy saving measures such as energy demand reduction and natural resources sustainable management, which are the very core of sustainability. 


\section{RES Integration Increase Potential on Islands}

A significant number of studies around the world focus on RES integration increase in the islands' microgrid, in order to reduce the environmental impacts of carbon use. Interconnected islands have the advantage of being part of mainland electrical grid and, therefore, could have a $100 \%$ renewable energy share. Similar studies have been conducted on Samsoe Island, Denmark [15], Fox Island, United States [16], and Pellworm Island, Germany [17].

Non-interconnected islands face the difficulties of having small electrical grids, such as intensely fluctuant frequencies and uncontrollable voltage [7]. Wind does not provide stable electricity supply, as it depends on the changing climatic conditions. There are penetration limitations due to technical minimum of conventional power plants, reliability, and network stability issues.

Studies on island grids powered by thermal plants recommend a $25 \%-35 \%$ maximum RES integration $[7,18,19]$. Neves et al. [19] argue that the most appropriate hybrid energy system for islands with a population greater than 5000 inhabitants is the combination of wind turbines, photovoltaic systems, and diesel engines. Studies for the Maldives [20] and Kutubdia Island, Bangladesh [21] illustrate the proposed strategy.

One of the most efficient ways to achieve higher RES integration rates, up to $100 \%$, in the energy grid is to store the produced energy locally. There are three main types of energy storage commonly used: pumped storage, hydrogen storage, and batteries.

Pumped storage is a relatively economical energy storage method and can be installed in large islands. However, it requires significant altitude difference and suitable terrain. The operation is based on pumping and storing water in a reservoir, which is located at high altitude, during periods of renewable energy production excess. The reserve is used to generate hydroelectric power during periods of energy shortage or in times of high offered selling price. There are numerous studies regarding the installation of hybrid power systems using pumped hydroelectric storage in literature, such as those of Canary Islands, Spain [22], and St. Vicente's Cape Verde Island [23].

Hydrogen energy storage is one of most expensive applications. Nevertheless, over the past few years, several studies have been conducted, making use of it on islands, including Porto Santo and Corvo Islands in the Azores of Portugal [24,25], Sicily Island, Italy [26], and Utsira Island in Norway [27].

Batteries are more efficiently applied to small electricity production systems because of their high installation cost. Their comparative advantage is that they can be applied anywhere, regardless of the geographical characteristics of the area. Similar studies have been published for Fiji Island [28] and Corsica Island [29].

It is worth mentioning that Neves et al. [19] claim that many studies that suggest RES penetration in island grids are demonstrations of technological development, which try to incorporate the latest technological advances in energy production and storage, without taking into account the existing features and capabilities of local energy systems.

Last, smart grids are a more useful tool for RES integration increase. Smart grids are used for the reliable and efficient bidirectional control of distributed energy resources under the same distribution grid. They are designed to reduce transmission losses, prevent unnecessary thermal plant installations, and facilitate RES integration [30]. Grid operator uses the generation and demand data in order to optimize the entire process. The application of smart grids does not abolish diesel engines. It turns them into backup energy production tools.

\section{The Energy Interconnection Potential of Greek Islands}

Greek islands face similar problems with those of the vast majority of islands around the world, which produce energy by autonomous oil units. Again, Mondol and Koumpetsos [31] claim that the main problems that islands face are the dependence on fossil fuels, the costly conventional electricity generation, the small size of power plants compared to the cabling alternative, and the seasonal-driven character of demand. 
Unfortunately, in Greece, the option of interconnection to the mainland is complicated because of the great number and the scattered nature of islands. However, according to Karamanou et al. [32], the criterion used in deciding whether to develop the interconnection or not, is the investment viability.

Figure 1 presents the interconnected and non-interconnected Greek islands. All islands of the Ionian Sea have been interconnected since the 1970s. Sporades Islands, the Argosaronic Gulf Islands and Kithira Island, Evia, Andros, and Tinos Islands have also been interconnected, as well as Thasos and Samothrace Islands in the North Aegean Sea. On the other hand, the number of the autonomous power plants of the Aegean Sea Islands is 56.

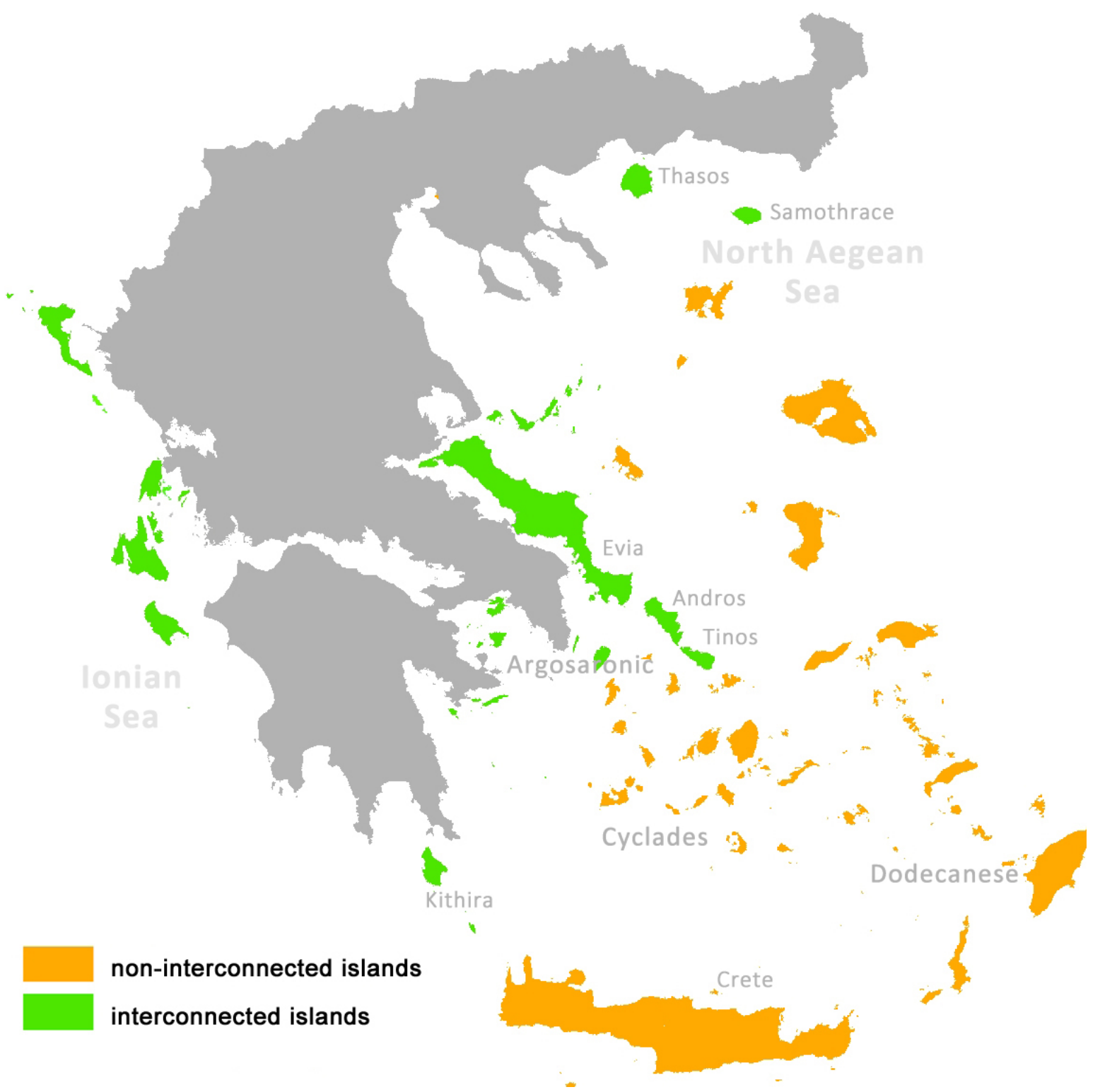

Figure 1. Interconnected and non-interconnect Greek islands [33].

During the last decades, the Greek scientific community has shown an increasing interest regarding the issue of islands' electricity interconnection to the mainland grid through a number of studies undertaken by the Public Power Corporation (PPC), the Regulatory Authority of Energy (RAE) and academic institutions [34-38]. More specifically, in 1988, PPC had conducted a study on the interconnection of Crete with the mainland grid and in 1989 a study for Cyclades interconnection. National Technical University of Athens had also conducted a number of studies for the interconnection 
of Cyclades in 2004-2005 [39] and the entire Aegean Sea, including Crete [40]. All interconnection proposals for the Aegean Sea Islands are illustrated in Figure 2.

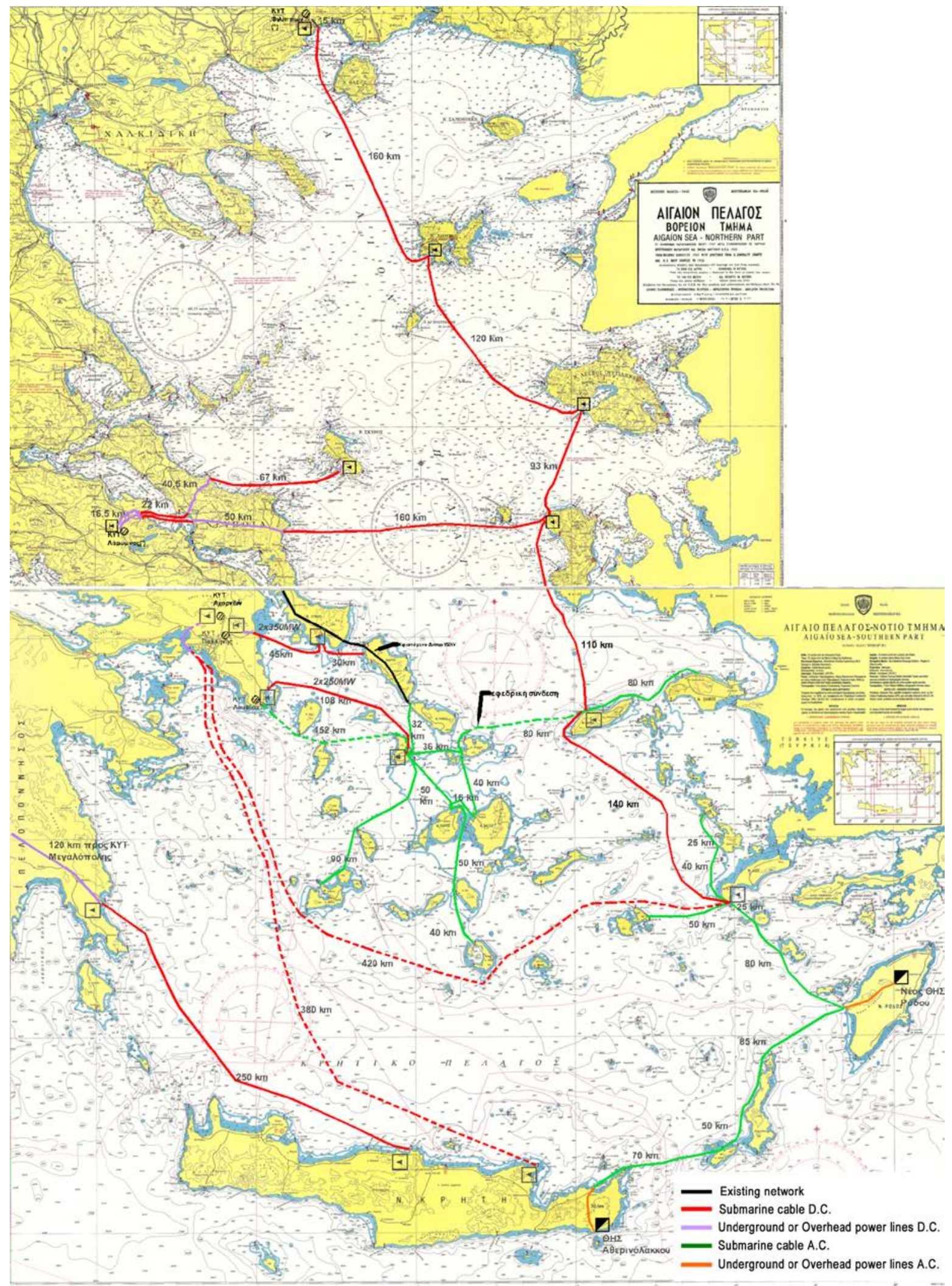

Figure 2. Interconnection proposals for the Aegean Sea Islands [41]. 
Similar studies have been carried out by independent power producers-who are willing to bear the cost of the interconnection to the mainland grid-in order to install large, in terms of power, WFs in islands, especially in Cyclades and the North Aegean Sea Islands. Comparing it with the already installed power, it is clear that future installations have to be large in scale in order to make power interconnection economically viable. This way, islands are given an enormous share of electricity production from wind energy.

It is worth mentioning that the issue of islands' interconnection came back to the fore in the 1990s because of the exploitability of high potential renewables (wind, solar) that the islands have. Several studies, both at international [16] and national level [42], propose extensive RES installations, much larger than the local energy demand. Hence, Mondol and Koumpetsos [31] claim that Greece will not reach the National Target for $20 \%$ RES penetration in the grid by 2020, unless the high wind potential of islands is exploited.

In many cases, the location and morphological characteristics of the islands incommode the interconnection to the mainland electrical grid, both technically and economically. As previously mentioned, the optimum solution to the issue of RES penetration increase for autonomous grids is the energy storage. There are several studies focused in Greek islands. In particular, for Limnos and Lesvos Islands, which are located in the northern Aegean Sea, there are researchers suggesting from medium-size penetration of wind and photovoltaic systems $[43,44]$ to hybrid wind systems and pumped storage installations [45], covering the energy needs of the islands with, up to $100 \%$, green energy [46]. At the southern Aegean Sea, Tzamalis et al. [47] have studied the autonomous energy system of Milos Island, based on wind energy and hydrogen storage units, while Sakellaridis et al. [48] introduce pumped storage for Crete's Island electrical grid.

\section{Case Study: The Dodecanese Islands}

The Dodecanese islands are located at the southeast of the Aegean Sea. It is a group of 27 inhabited and more than 100 uninhabited islands, occupying an area of $2714 \mathrm{~km}^{2}$. Rhodes, Kos, and Karpathos are the largest and most densely populated. Morphologically, the Dodecanese soil is barren and rocky. Forty-two percent of the total area is flat, $26 \%$ is semi-mountainous, and $32 \%$ mountainous, while forests and woodlands cover approximately $50 \%$ of the total area.

Regarding the local economy, the trade sector, along with tourist accommodation and food-service establishments, generate the largest gross value added amount of the region. Hence, there are discrete areas of exclusive tourism use, mainly located in Rhodes, Kos, and Karpathos Islands, while on the rest of the islands, tourism coexists with permanent or seasonal residence [49]. Figure 3 shows an informative map of the spatial organization of tourism, provided by the Special Framework for Spatial Planning and Sustainable Development for Tourism (Tourism-SFSPSD) [50]. According to Figure 3, the northern part of Rhodes and Kos Islands (red colour) is categorised as already-developed touristic areas, while the rest of the islands as developing, testifying to the intense touristic activity of the area (orange and yellow colours).

Agriculture, livestock, and fishing are traditional economic activities of the area. The fishing industry is of particular importance as it supplies both the domestic and international market. The local aquaculture production is ranked third in the national exports, exporting near two-thirds of the total production [49]. 


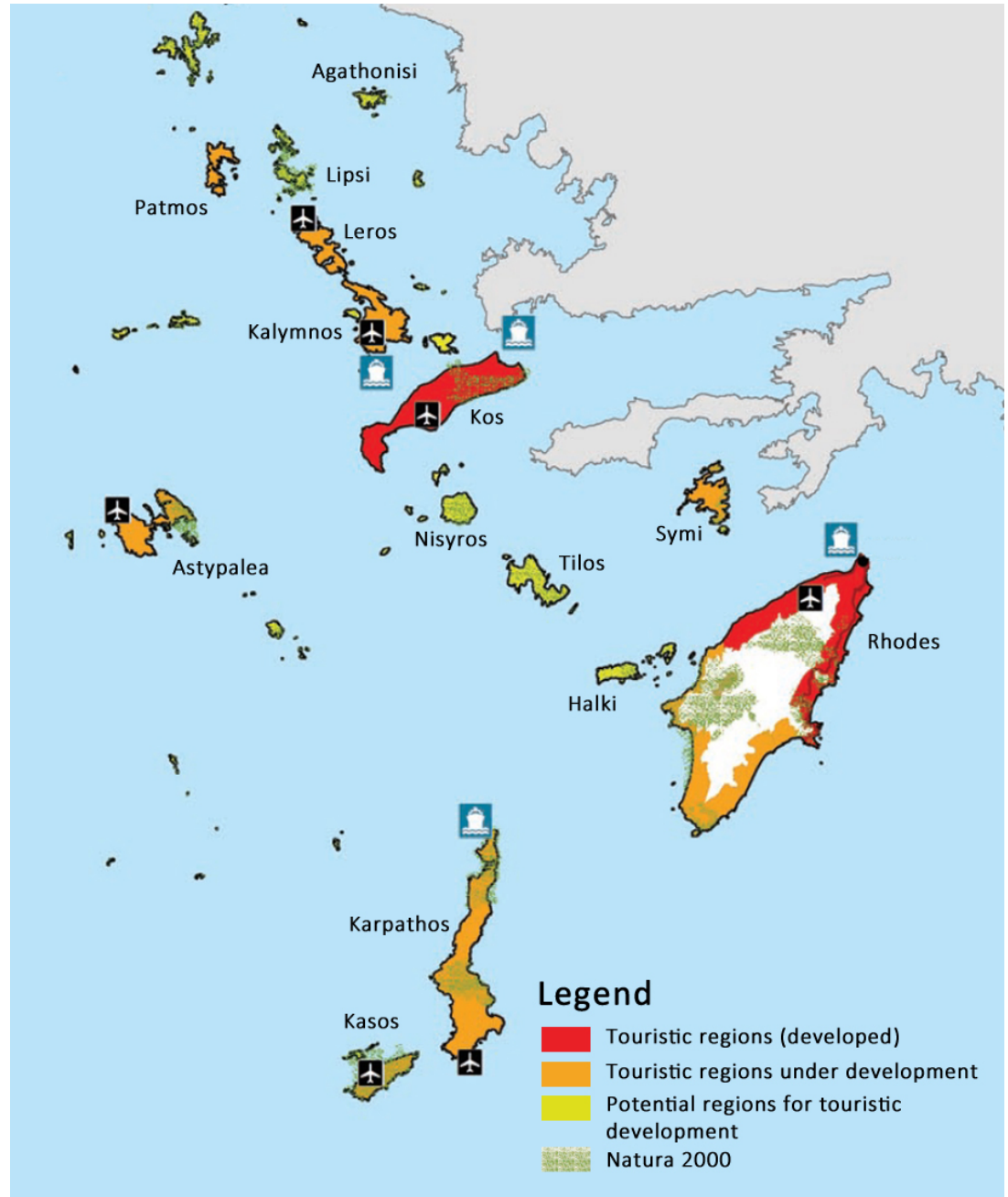

Figure 3. Spatial organization of tourism [50].

\subsection{Energy Features}

The electrical grid of the Dodecanese islands is fragmented and spread across a long distance, consisting of a number of small and medium scale electrical grids that serve the energy needs of a single island or a group of islands. Today, 11 autonomous electrical systems (AES) can be found, including various types of power plants, mainly thermal oil units. As shown in Table 1, the largest one, in terms of service area and interconnected islands, is the AES of Kos-Kalymnos, serving eight islands (Kos, Kalymnos, Leros, Nisyros, Tilos, Lipsi, Gyali, and Telendos Islands). In terms of installed capacity and energy production, the largest one is the AES of Rhodes.

The local energy consumption pattern seems to follow the rapid development of tourism. In 10 years' time, from 2000 to 2010 , energy demand had increased by $43.7 \%$, which is double the country's equivalent percentage, lying at $20.5 \%$. Figure 4 shows the annual energy consumption of the area concerning the last 20 years. 
Table 1. Installed capacity of conventional units and wind farm (WF) energy production per electrical system, year 2014 [51].

\begin{tabular}{|c|c|c|c|}
\hline $\begin{array}{l}\text { Autonomous } \\
\text { Power Plants }\end{array}$ & $\begin{array}{l}\text { Powered } \\
\text { Islands }\end{array}$ & $\begin{array}{l}\text { Installed Capacity of } \\
\text { Thermal Units (MW) }\end{array}$ & $\begin{array}{l}\text { Installed Capacity of } \\
\text { Wind Farms (MW) }\end{array}$ \\
\hline \multirow{2}{*}{ Rhodes (Soroni) } & Rhodes & 218.08 & 49.15 \\
\hline & Halki & 0 & 0 \\
\hline Agathonisi & Agathonisi & 0.51 & 0 \\
\hline Astypalea & Astypalea & 3.60 & 0 \\
\hline Megisti & Megisti & 1.82 & 0 \\
\hline Patmos & Patmos & 6.60 & 1.20 \\
\hline \multirow{9}{*}{ Kos-Kalymnos } & Kos & 101.90 & 11.20 \\
\hline & Kalymnos & 18.15 & 0 \\
\hline & Leros & 0 & 4.00 \\
\hline & Nisyros & 0 & 0 \\
\hline & Tilos & 0 & 0 \\
\hline & Lipsi & 0 & 0 \\
\hline & Gyali & 0 & 0 \\
\hline & Teledos & 0 & 0 \\
\hline & Pserimos & 0 & 0 \\
\hline \multirow{2}{*}{ Karpathos } & Karpathos & 17.90 & 1.23 \\
\hline & Kasos & 0 & 0 \\
\hline Arki & Arki & 0.36 & 0 \\
\hline Symi & Symi & 8.20 & 0 \\
\hline Total & & 386.38 & 66.78 \\
\hline
\end{tabular}

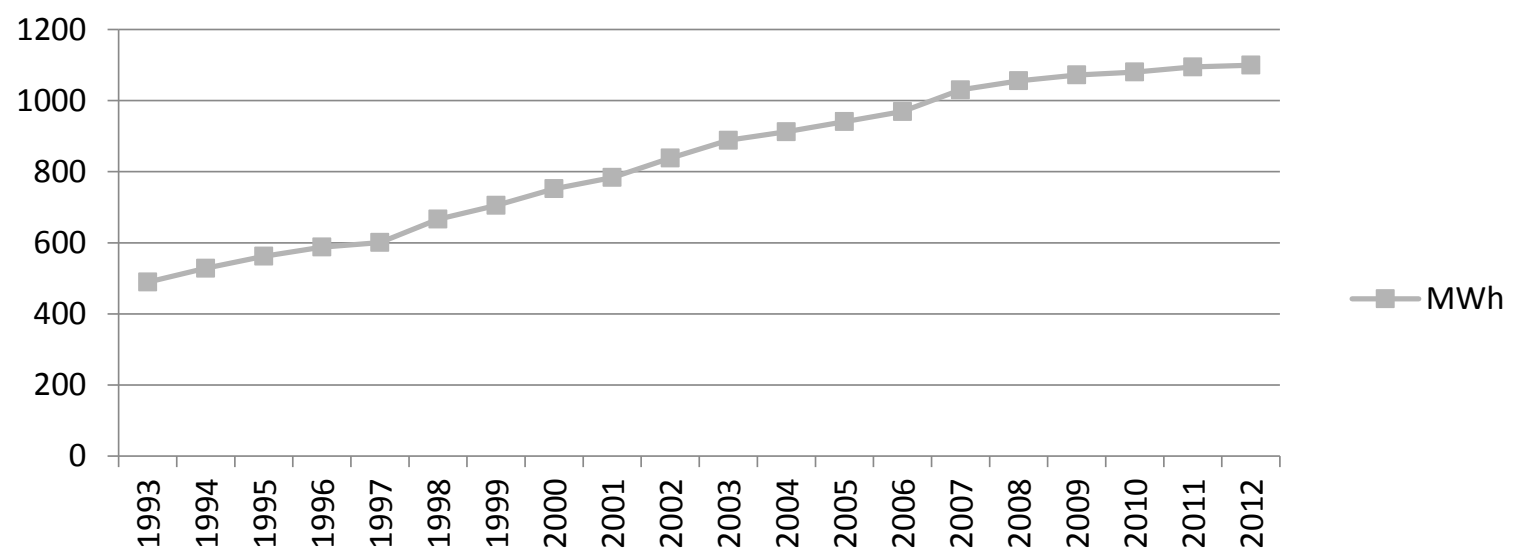

Figure 4. Annual energy consumption of the Dodecanese [52].

Unfortunately, there are no available data provided by HSA concerning the energy consumption per municipality or town/village. Therefore, a conversion formula, proposed by Tegou et al. [53], will be used in order to convert the data from country level to municipality level, for year 2012, as shown in Table 2 and Figure 5. It is evident that the municipalities of Rhodes, Kos, and Kalymnos hold the highest values, reaching altogether $88 \%$ of the total energy consumption of the area. 


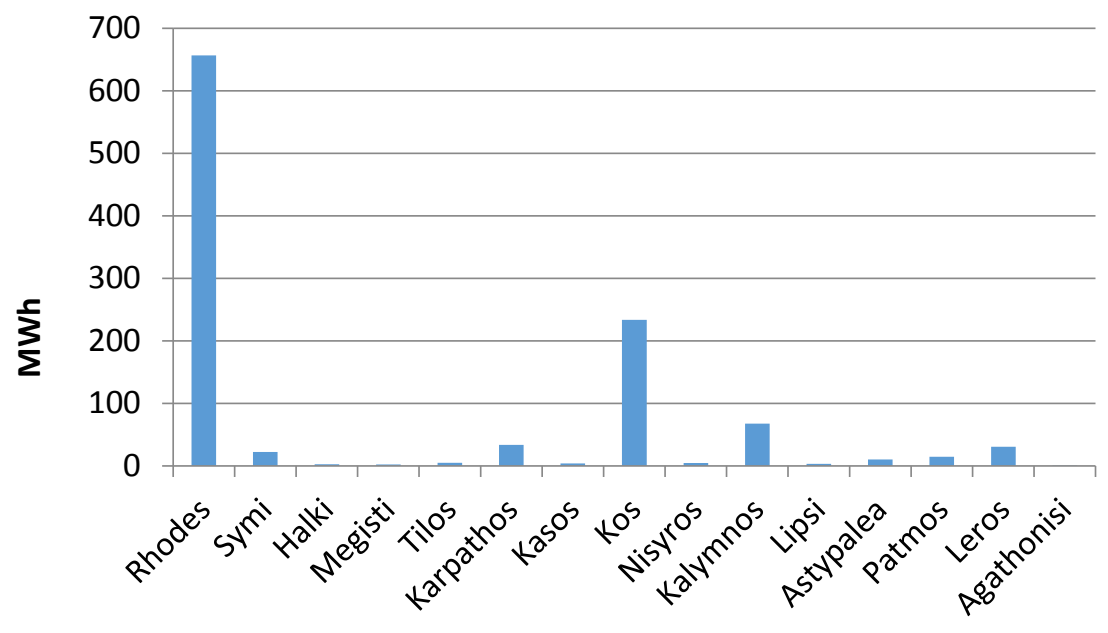

Figure 5. Annual energy consumption per municipality for the year 2012.

Table 2. Electricity consumption reduction (electricity demand) at village and agricultural land level, year 2012 [53].

\begin{tabular}{cccc}
\hline Sector & Sub-Sector & Data & Source \\
\hline Domestic & - & Population & {$[54]$} \\
\hline Commercial & Tourism $(50 \%)$ & Accommodation/Overnight stays & {$[55]$} \\
& General Trade (50\%) & Retail Stores & {$[56]$} \\
\hline Industrial & - & Manufacturers & {$[56]$} \\
Agricultural & - & Agriculture & {$[57]$} \\
Public services & - & Population & {$[54]$} \\
Road network lighting & - & Area occupied by village & {$[58]$} \\
\hline
\end{tabular}

As mentioned above, a key feature of the Dodecanese islands' consuming behavior is the high seasonal demand, caused by tourism during summertime. Figure 6 highlights the monthly energy consumption of the two larger energy systems, Rhodes and Kos-Kalymnos, where the peak summer production is twice the lower during winter.

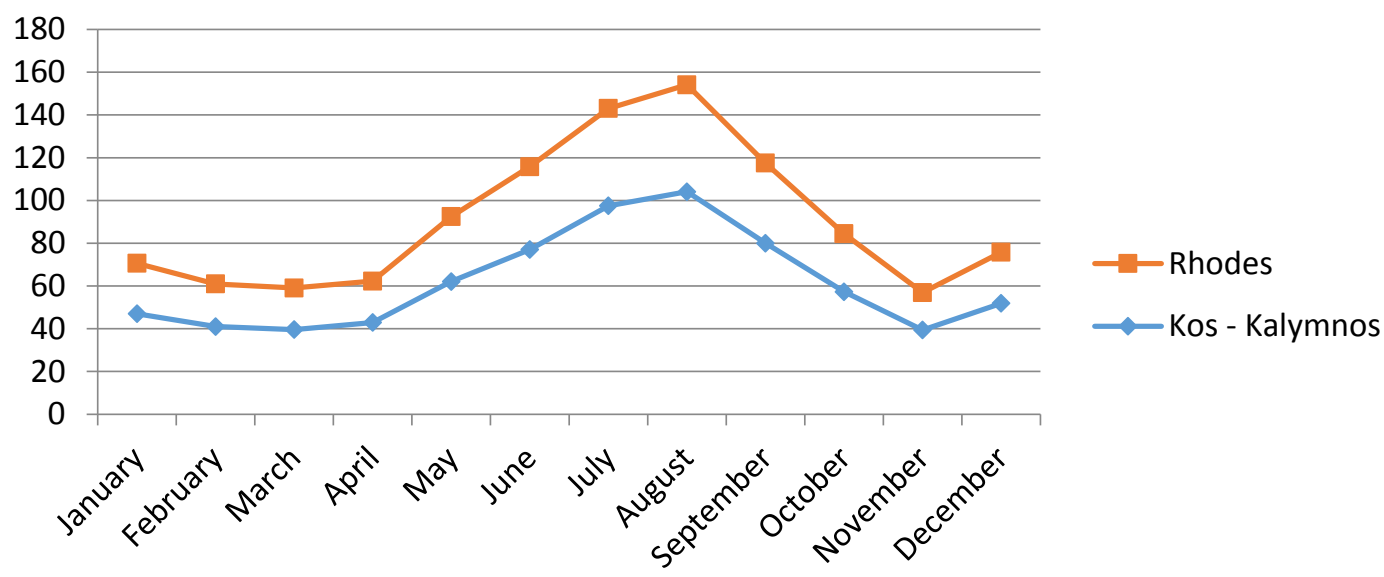

Figure 6. Energy production for the electric energy systems of Rhodes and Kos-Kalymnos, for the year 2013 [51]. 


\subsection{Renewable Energy Sources}

The Dodecanese islands are of great RES potential, mainly of solar and wind energy. The study of the Centre for Renewable Energy Sources and Saving [59] on the wind energy potential of the country indicates that the vast majority of the Dodecanese areas show a high wind average speed of more than $7 \mathrm{~m} / \mathrm{sec}$, as shown in Figure 7. It should also be mentioned that there is a remarkable geothermal potential (high and low enthalpy geothermal fields) in Nisyros Island.

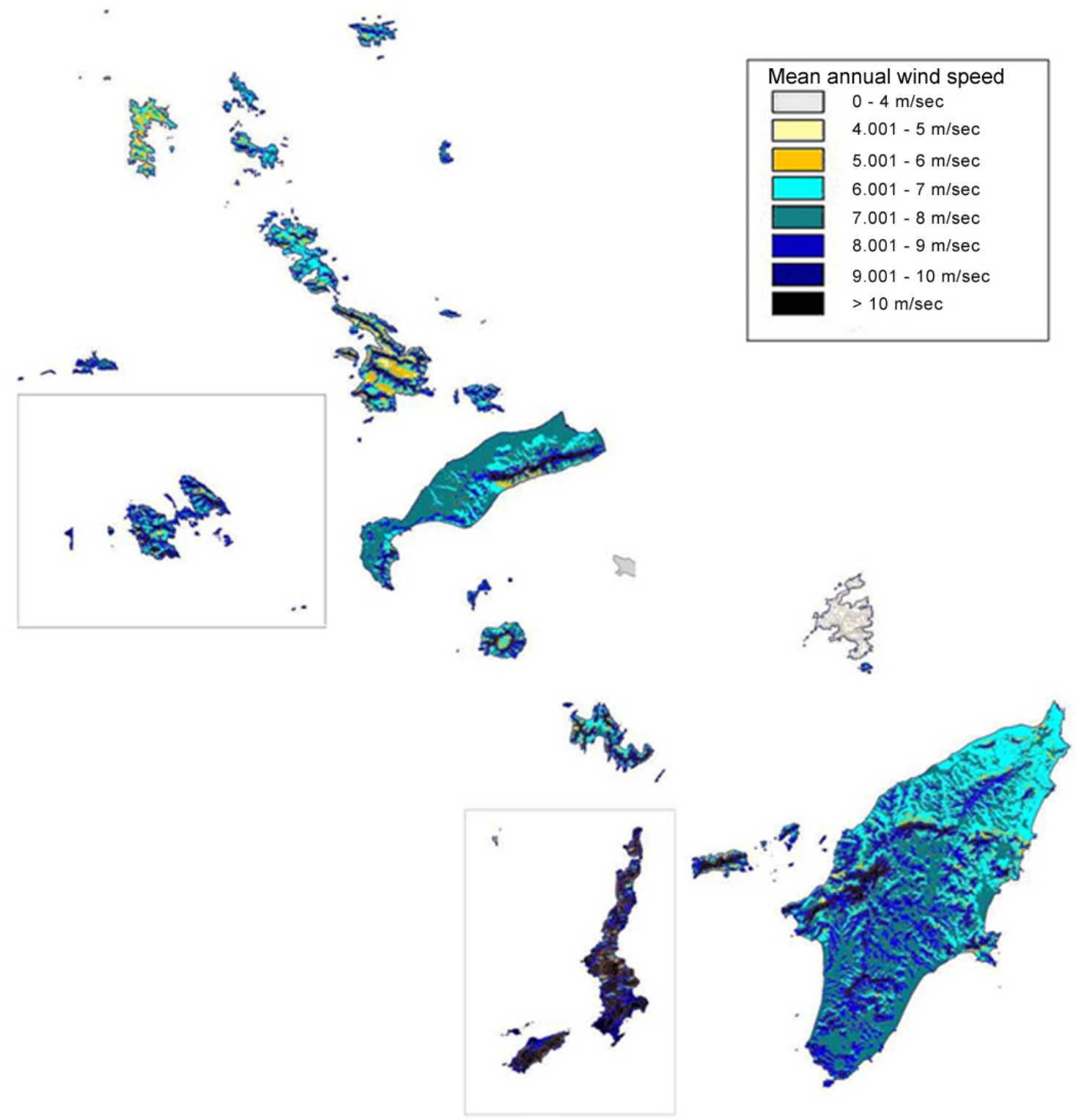

Figure 7. Thematic map for the estimation of the technically and economically exploitable potential of wind energy in the Dodecanese islands [59].

However, the exploitation of RES for electricity production has started over the last 15 years. According to Table 1, today, the installed capacity of WFs reaches 14\%, while the produced energy does not exceed the average of $10 \%$, as shown in Figure 8 . It is assumed that despite the enormous development possibilities, the degree of exploitation and penetration of wind energy in AES is comparably low. 


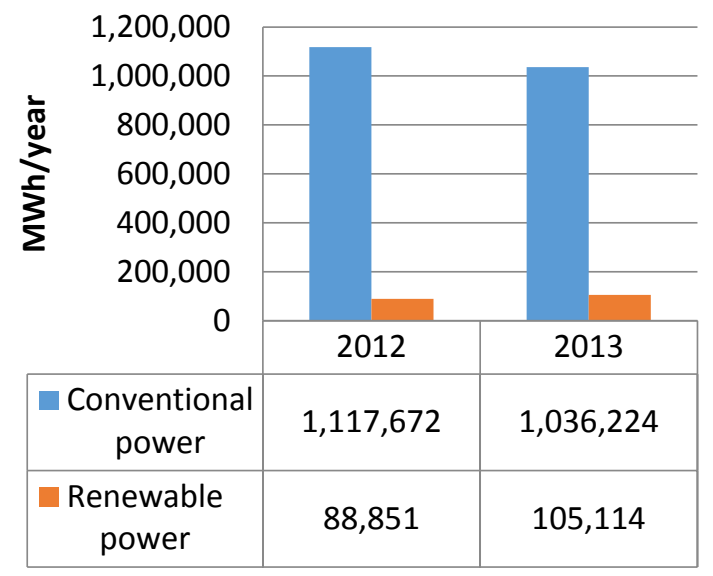

Figure 8. Participation rates of conventional and renewable power plants in energy production in 2012 and 2013 [51].

According to the National Action Plan for RES, the total installed capacity of WFs in Greece should reach $7.5 \mathrm{GWs}$ in 2020. The share that proportionally corresponds to the Dodecanese islands, based on the current electricity demand and the installed capacity of the area, is shown in Table 3. According to HSA's unpublished results for year 2012, the energy consumption of the Dodecanese corresponds to $2.15 \%$ of the country, and therefore to $161.25 \mathrm{MW}$ installed capacity by 2020 . As expected, the vast majority of wind power plants should be installed in the islands of Rhodes, Kos, and Kalymnos. Comparing it with the maximum power capacity (in the case of interconnection), provided by Law, it can be assumed that there is still a great renewable energy exploitation potential.

Table 3. Estimated installed capacity for each of the Dodecanese islands in 2020, according to the National Action Plan "20-20-20", based on the current status of energy consumption.

\begin{tabular}{ccccc}
\hline Island & $\begin{array}{c}\text { Energy Consumption } \\
\text { Island/Dodecanese } \\
\mathbf{( \% )}\end{array}$ & $\begin{array}{c}\text { Wind Power to be } \\
\text { Installed by } \mathbf{2 0 2 0} \\
\text { (MW) }\end{array}$ & $\begin{array}{c}\text { Total Installed } \\
\text { Power by 2020 } \\
\text { (MW) }\end{array}$ & $\begin{array}{c}\text { Maximum Power } \\
\text { Capacity (in the Case of } \\
\text { Interconnection) (MW) }\end{array}$ \\
\hline Kos & $21.42 \%$ & 34.54 & 45.74 & 152.43 \\
Nisyros & $0.42 \%$ & 0.67 & 0.67 & 21.87 \\
Patmos & $1.34 \%$ & 2.17 & 3.37 & 18.10 \\
Astypalea & $0.93 \%$ & 1.50 & 1.50 & 36.79 \\
Agathonisi & $0.06 \%$ & 0.10 & 0.10 & 7.11 \\
Kalymnos & $6.20 \%$ & 10.00 & 10.00 & 58.61 \\
Lipsi & $0.29 \%$ & 0.47 & 0.47 & 8.40 \\
Leros & $2.81 \%$ & 4.54 & 8.53 & 159.65 \\
Karpathos & $3.07 \%$ & 4.95 & 6.18 & 35.20 \\
Kasos & $0.37 \%$ & 0.60 & 0.60 & 30.67 \\
Symi & $2.04 \%$ & 3.29 & 3.28 & 34.18 \\
Tilos & $0.44 \%$ & 0.71 & 0.71 & 14.31 \\
Halki & $0.24 \%$ & 0.38 & 0.38 & 4.83 \\
Megisti & $0.21 \%$ & 0.33 & 0.33 & 742.77 \\
Rhodes & $60.16 \%$ & 97.00 & 146.15 & 1353.00 \\
Total & $100 \%$ & 161.25 & 228.03 & \\
\hline
\end{tabular}

On the other hand, according to Hellenic Transmission System Operator, the total capacity of WF investment applications by 2010 was $4717.6 \mathrm{MW}$ [41]. Figure 9 presents WF applications that have already been lodged for the Dodecanese Islands. The juxtaposition of Figure 9 with the wind energy potential map of Figure 7 reveals that most WF applications are located in windy areas, regardless of the energy needs of the islands and the local RES integration potential. 


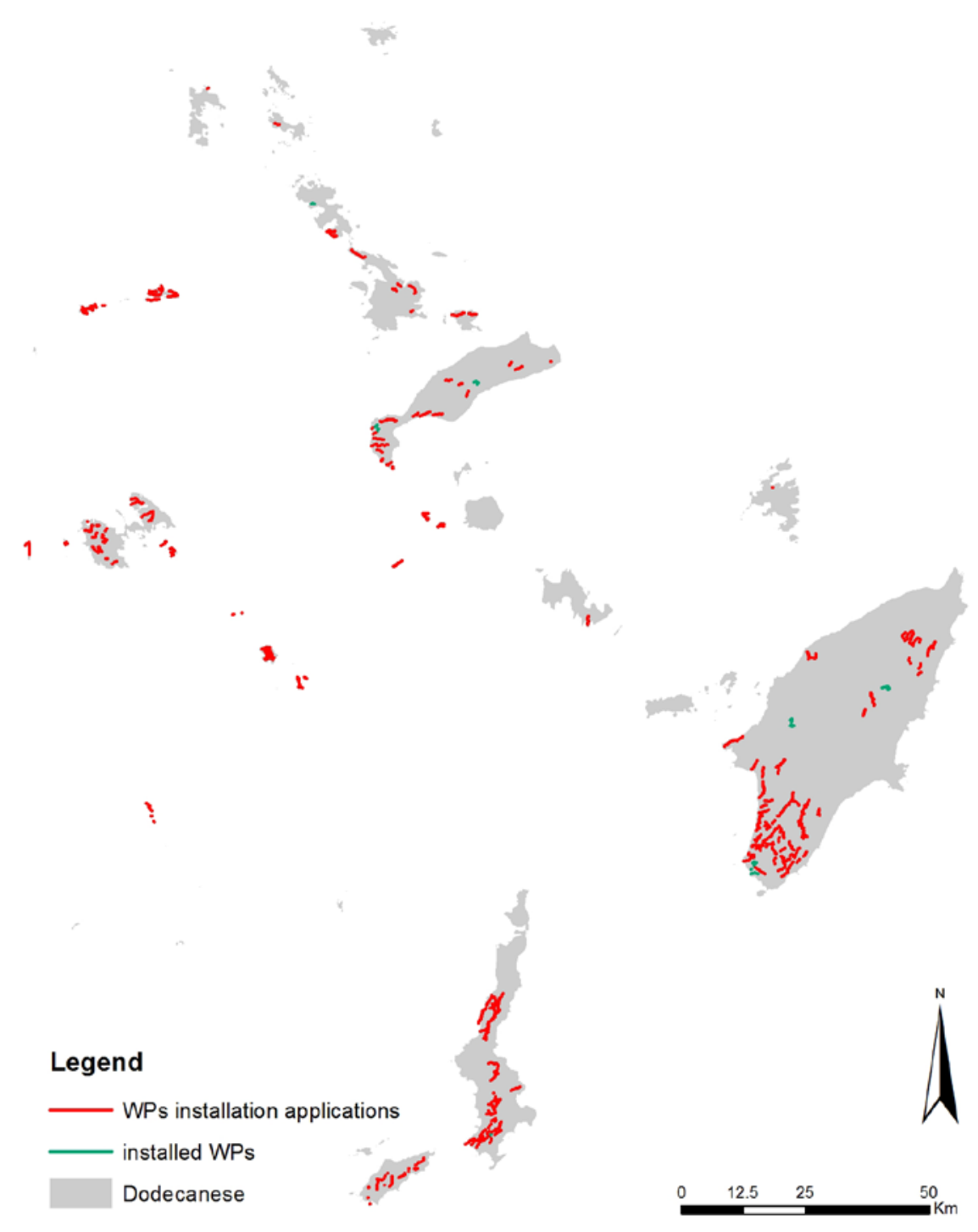

Figure 9. Installed WPs and WPs installation applications for the Dodecanese.

\subsection{Studies for RES Integration Increase}

Several studies deal with the potential use of renewables for electricity production in Greek islands [60], while others calculate the optimal rate of RES penetration in the AES, using the life cycle analysis method [44]. For example, Kaldellis et al. [45] work on the autonomy of Agathonisi Island, suggested wind and solar power installations, accompanied by a battery storage system or the use of energy surplus for desalination and a backup diesel engine. For the electrical system of Karpathos-Kasos, which has a remarkably high wind potential, Katsaprakakis et al. [61] argue that it is possible to achieve very high RES penetration rates through the installation of WFs and seawater pumped storage system. In fact, they propose the installation of these two activities in a different island for the balanced distribution of the energy production weights. Part of the research group suggests the same method for the electrical system of Rhodes [62].

\subsection{Interconnection Prospects}

Based on HEDNO's latest study-proposal on the interconnection of the Aegean islands to the mainland grid [41], there are three scenarios, illustrated in Figure 2:

1. Expansion of Chios DC loop to Kos and the Dodecanese. 
Due to the high investment interest shown for the development of WFs on islands or islets around Kos and Astypalea Islands, both onshore and offshore, the extension of the DC loop proposed for the interconnection of the Northeast Aegean (Chios and Samos), which will be extended to Kos first and then to Rhodes and Nisyros, is under examination. The cost is high; however, the absorption capacity of wind power will reach approximately $350 \mathrm{MW}$.

2. Interconnection with Crete.

After the interconnection of Crete with the electrical grid of the mainland, there is a proposal for the interconnection of the Dodecanese Islands, through Kasos and Karpathos Islands to Rhodes. Afterwards, the network will be extended through Nisyros to Kos and then to Astypalea, Kalymnos and Leros. The cable length is calculated approximately to $450 \mathrm{~km}$ and its power absorption capability to $700 \mathrm{MW}$.

3. Interconnection with the National Interconnected Transmission System (Attica).

As previously stated, there is high investors' interest in installing WFs in the area, due to the high wind potential. This is the reason why the possibility of Kos' electrical interconnection straight to Attica is under consideration.

Obviously, the main purpose of all three scenarios is to achieve the maximum exploitation of the high wind potential of the area. This argument is better illustrated by the third scenario, which proposes the interconnection of remoted islands and islets straight to Attica, a venture of high cost and significant energy losses.

\section{Discussion and Conclusions}

An integrated energy policy necessarily entails the recording of national, local and sectoral energy needs (domestic, industrial, tourism, trade, transport, etc.) and the specification of any exclusion areas for power plant sitting, in order to protect the natural and human environment. However, what actually happens in Greece is the formation of a national target, exclusively based on European Directives, more specifically Directive 2009/28/EC. As mentioned, in order for the goals to be achieved, the current legislative framework provides mapping of priority areas, which have been developed under two major criteria: wind power and proximity to electricity infrastructure. Unfortunately, there is no indication of excluded areas, not to mention local specifics. At the same time, there is also no specific provision for islands, as they are treated almost the same way as the mainland. The only restriction that has been set for non-interconnected islands is the maximum WF energy capacity they can bear, which is twice the peak level of energy demand, calculated for a 10-year plan. For example, based on the current energy consumption pattern of Figure 4, Rhodes Island's energy consumption is expected to rise by $45 \%$ in the next 10 years. Taking into consideration the seasonal demand of Figure 6 , the peak energy demand is expected to reach $200 \mathrm{MWh}$ by 2020. It is understood that the amount of $400 \mathrm{MW}$ cannot be integrated into the energy network of the island, unless it undergoes radical upgrades. At the same time, the number of wind turbines that need to be installed is going to alter the island's landscape, having considerable impact on the touristic activity of the area.

The National Target for RES and the existing legislative framework focus on the installation of great RES power on the Greek islands. It is clear that the increased private interest on islands' interconnection serves the same goal. The vast majority of WF installation applications are large-scale investments of hundreds of MWs, located in windy areas that require the energy interconnection to the mainland. Once more, they are located in areas of high wind potential, regardless of the size of the island and the local energy needs. This is illustrated in Figure 5 where Astypalea Island and the surrounding islets (the westernmost island) and Kasos Island (the southernmost island) have a great number of applications, despite the fact that they are small in size and population. All the above put more stress on the islands to bear the weight of the electrification of urban areas, increasing spatial inequalities. 
A medium-term proposal for the Dodecanese islands, in respect to the local energy needs and activities, is the interconnection of the two larger electrical networks (Rhodes and Kos-Kalymnos) which are in close proximity and serve 11 islands. The scattered installation of the number of WFs that can be integrated by the local electrical grid will increase RES penetration and stability of the energy supply. There are steps to be made for RES integration increase in Greek islands, in the long term. The academia has provided a great number of proposals which have to be studied in depth, taking into account local constraints and future needs.

Acknowledgments: The authors wish to thank the (Greek) State Scholarships Foundation-Scholarships of Excellence for postgraduate studies in Greece: IKY-SIEMENS Program, for the financial support provided to Maria Panagiotidou.

Author Contributions: Maria Panagiotidou is the main author and was responsible for the literature review, the methodology created and the data analysis presented in this paper. George Xydis and Christopher Koroneos were scientific collaborators who guided the work of this paper and suggested critical amendments. They also contributed revisions of the original text provided by the main author. Christopher Koroneos is the professor guiding the present group of researchers and provided feedback on the assumptions, methods and conclusions of the paper.

Conflicts of Interest: The authors declare no conflict of interest. The funding sponsors had no role in the design of the study; in the collection, analyses, or interpretation of data; in the writing of the manuscript, and in the decision to publish the results.

\section{Abbreviations}

WFs
RES
RES-SFSPSD
AES
Tourism-SFSPSD
HEDNO
HSA
RAE

\section{References}

1. Malta \& Canada Agenda Academic \& Institute of Island Studies. A World of Islands: An Island Studies Reader; Institute of Island Studies: Charlottetown, PE, Canada, 2007.

2. Janeiro, R. United Nations Conference on Environment \& Development, Brazil, 3-14 June 1992. Agenda 21. Available online: https://sustainabledevelopment.un.org/content/documents/Agenda21.pdf (accessed on 7 December 2014).

3. UN. Report of the Global Conference on the Sustainable Development of Small Island Developing States. In Proceedings of Global Conference on the Sustainable Development of Small Island Developing States, Bridgetown, Barbados, 25 April-6 May 1994.

4. European Commission. A Energy for the Future: Renewable Sources of Energy-White Paper for a Community Strategy and Action Plan; Europe Information Service: Brussels, Belgium, 1998.

5. INSULA. Minorca Commitments-European Islands Agenda. In Proceedings of 1st European Conference on Sustainable Island Development, Minorca, Spain, 23-26 April 1997.

6. Gori, F.; Ludovisi, D.; Cerritelli, P. Forecast of oil price and consumption in the short term under three scenarios: Parabolic, linear and chaotic behaviour. Energy 2007, 32, 1291-1296. [CrossRef]

7. Notton, G.; Stoyanov, L.; Ezzat, M.; Lararov, V.; Diaf, S.; Cristofari, C. Integration limit of renewable energy systems in small electrical grid. Energy Proc. 2011, 6, 651-665. [CrossRef]

8. Koroneos, C.; Xydis, G.; Polyzakis, A. The optimal use of renewable energy sources-The case of Lemnos Island. Intern. J. Green Energy 2013, 10, 860-875. [CrossRef]

9. EC. Communication from the Commission to the European Council and the European Parliament-An Energy Policy for Europe; Europe Information Service: Brussels, Belgium, 1997.

10. GWEA, 2008. Critical Analysis of the SFSPSD-RES sustainability value. Greek Wind Energy Association, Athens. Available from: http:/ / eletaen.gr/category/politics-articles/ (accessed on 20 December 2014). 
11. CES, 2010. Renewable Energy Sources as an Effective Environmental Protection Tool: Application Issues and Interpretation of Environmental and Forest Legislation. Chamber of Environment and Sustainability: Athens, 2015. Available online: http://eletaen.gr/ $\alpha \pi \varepsilon-\pi \varepsilon \rho \iota \beta \alpha \lambda \lambda \mathrm{o} v \tau \iota \kappa \eta-\pi \rho \circ \sigma \tau \alpha \sigma \iota \alpha /$ (accessed on 20 December 2014).

12. Hatzivasiliadis, G. Problems the Ambitious Goal of RES Penetration in Electricity Production Face. Available online: http:/ / www.capital.gr/Articles.asp?id=1132287 (accessed on 12 December 2014).

13. Morrison, M.; Sinclair, K. Wind Energy Technology, Environmental Impacts of. Encyclopedia Energy 2004, 6, 435-448.

14. Katsoulakos, N.; Kaliabakos, D. Renewable Energy Sources and Mountainous Areas. In Proceedings of the 6th Interdisciplinary Interuniversity Conference of the NTUA and MEGDE NTUA, The Integrated Development of Mountainous Areas, Metsovo, Greece, 16-19 September 2010.

15. Gipe, P. Samsø: Denmark's Renewable Energy Island. 2006. Available online: http://www.wind-works. org/cms/index.php?id=61\&tx_ttnews\%5Btt_news\%5D=509\&cHash=35eee78d717826e522532cf952e2137e (accessed on 21 November 2014).

16. Dua, M.; Manwell, J.; McGowan, J. Utility scale wind turbines on a grid-connected island: A feasibility study. Renew Energy 2008, 33, 712-719.

17. ISRER, internet. Pellworm Island-Germany International Study of RE-Regions. Available online: http: / / reregions.blogspot.pt/2010/03/pellworm-island.html (accessed on 24 November 2014).

18. Papathanassiou, S.; Boulaxis, N. Power limitations and energy yield evaluation for wind farms operating in island systems. Renew Energy 2006, 31, 457-479. [CrossRef]

19. Neves, D.; Silva, C.; Connors, S. Design and implementation of hybrid renewable energy systems on micro-communities: A review on case studies. Renew. Sustain. Energy Rev. 2014, 31, 935-946. [CrossRef]

20. Van Alphen, K.; Van Sark, W.; Hekkert, M. Renewable energy technologies in the Maldives-determining the potential. Renew. Sustain. Energy Rev. 2007, 11, 1650-1674. [CrossRef]

21. Nandi, S.; Ghosh, H. Techno-economic analysis of off-grid hybrid systems at Kutubdia Island, Bangladesh. Energy Policy 2010, 38, 976-980. [CrossRef]

22. Bueno, C.; Carta, J. Wind powered pumped hydro storage systems, a means of increasing the penetration of renewable energy in the Canary Islands. Renew. Sustain. Energy Rev. 2006, 10, 312-340. [CrossRef]

23. Segurado, R.; Krajacic, G.; Duic, N.; Alves, L. Increasing the penetration of renewable energy resources in S. Vicente, Cape Verde. Appl. Energy 2011, 88, 466-472. [CrossRef]

24. Duic, N.; Carvalho, M. Increasing renewable energy sources in island energy supply: Case study Porto Santo. Renew. Sustain. Energy Rev. 2004, 8, 383-399. [CrossRef]

25. Parissis, O.S.; Zoulias, E.; Stamatakis, E.; Sioulas, K.; Alves, L.; Martins, R.; Tsikalakis, A.; Hatziargyriou, N.; Caralis, G.; Zervos, A. Integration of wind and hydrogen technologies in the power system of Corvo Island, Azores: A cost-benefit analysis. Int. J. Hydrogen Energy 2011, 36, 8143-8151. [CrossRef]

26. Matera, V.; Sapienza, C.; Andaloro, L.; Dispensa, G.; Ferraro, M.; Antonucci, V. An integrated approach to hydrogen economy in Sicilian Islands. Int. J. Hydrogen Energy 2009, 34, 7009-7014. [CrossRef]

27. Ulleberg, Ø.; Nakken, T.; Eté, A. The wind/hydrogen demonstration system at Utsira in Norway: Evaluation of system performance using operational data and updated hydrogen energy system modelling tools. Int. J. Hydrogen Energy 2010, 35, 1841-1852. [CrossRef]

28. Krumdieck, S.; Hamm, A. Strategic analysis methodology for energy systems with remote island case study. Energy Policy 2009, 37, 3301-3313. [CrossRef]

29. Diaf, S.; Belhamel, M.; Haddadi, M.; Louche, A. Technical and economic assessment of hybrid photovoltaic/wind system with battery storage in Corsica Island. Energy Policy 2008, 36, 743-754. [CrossRef]

30. Reddy, K.; Kumar, M.; Mallick, T.; Sharon, H.; Lokeswaran, S. A review of Integration, Control, Communication and Metering (ICCM) of renewable energy based smart grid. Renew. Sustain. Energy Rev. 2014, 38, 180-192. [CrossRef]

31. Mondol, J.; Koumpetsos, N. Overview of challenges, prospects, environmental impacts and policies for renewable energy and sustainable development in Greece. Renew. Sustain. Energy Rev. 2013, 23, 431-442. [CrossRef]

32. Karamanou, E.; Papathanassiou, S.; Papadopoulos, M. Planning the Interconnection of islands to the Mainland Grid via Submarine Cables. In Proceedings of MedPower Conference, Thessaloniki, Greece, 2-5 November 2008. 
33. RAE. Interconnected and Non-Interconnected Islands to the Electric Grid of the Mainland, 2015. Available online: http://www.rae.gr/site/categories_new/electricity/market/mdn.csp (accessed on 20 December 2014).

34. Boulaxis, N.; Papathanassiou, S.; Papadopoulos, M. Interconnection of the Cyclades Islands with the Mainland System to Increase Wind Power Penetration. Greek CIGRE Session 02. Athens, Greece, April 2002. Available online: http://www.ceer.eu/portal/page/portal/EER_HOME/EER_WORKSHOP/CEERERGEG\%20EVENTS/Electricity/WS-04_ELECTRICITY\%20INFRASTRUCTURE/Tab1/HTSO.ppt (accessed on 14 July 2016).

35. Georgiou, P.; Mavrotas, G.; Diakoulaki, D. The effect of islands' interconnection to the mainland system on the development of renewable energy sources in the Greek power sector. Renew. Sustain. Energy Rev. 2011, 15, 2607-2620. [CrossRef]

36. Karamanou, E.; Papathanassiou, S.; Boulaxis, N. Operating Policies for Autonomous Island Grids with PV Penetration. In Proceedings of 4th European PV-Hybrid and Mini-Grid Conference, Athens, Greece, 29-30 May 2008.

37. Papadopoulos, M.; Boulaxis, N.; Tsilis, M.; Papathanasiou, S. Interconnection of the Cycladic Islands to the Mainland Grid. In Proceedings of the 5th WSEAS International Conference on Power Systems and Electromagnetic Compatibility, Corfu, Greece, 23-25 August 2005.

38. Papadopoulos, M.; Boulaxis, N.; Tsili, M.; Papathanassiou, S. Increased wind energy exploitation via interconnection of Aegean Islands to the mainland grid. In Proceedings of CIRED', Vienna, Italy, 21-24 May 2007.

39. NTUA, 2004. Preliminary Study of the Cyclades Interconnection with Mainland Electricity System. Athens: Electrical and Computer Engineering Department-Electric Power Sector. Available online: http:/ / www.rae.gr/old/cases/C11/index.html (accessed on 25 March 2014).

40. ICCS-NTUA. Strategic Study of the Interconnection of Autonomous Island Power Systems: Final Report. Institute of Communication and Computer Systems, Athens. Available online: http://www.rae.gr/old/ cases/C19/ (accessed on 28 November 2014).

41. HTSO. Interconnections Study of the Aegean Islands to the Mainland Energy System—Phase I-General Design. Hellinic Transmission System Operator, Athens. Available online: http://www.desmie. gr/fileadmin/user_upload/Files/study/AIGAIA_DIASYNDESI_FASI_A_PERILIPSI.pdf (accessed on 12 February 2014).

42. Xydis, G. A techno-economic and spatial analysis for the optimal planning of wind energy in Kythira Island, Greece. Int. J. Prod. Econ. 2013, 146, 440-452. [CrossRef]

43. Giannoulis, E.D.; Haralambopoulos, D.A. Distributed generation in an isolated grid: Methodology of case study for Lesvos-Greece. Appl. Energy 2011, 88, 2530-2540. [CrossRef]

44. Koroneos, C.; Zairis, N.; Charaklias, P.; Moussiopoulos, N. Optimization of energy production system in the Dodecanese Islands. Renew. Energy 2005, 30, 195-210. [CrossRef]

45. Kaldellis, K.; Gkikaki, A.; Kaldelli, E.; Kapsali, M. Investigating the energy autonomy of very small non-interconnected islands. A case study: Agathonisi, Greece. Energy Sustain. Dev. 2012, 16, 476-485. [CrossRef]

46. Xydis, G. Comparison study between a Renewable Energy Supply System and a supergrid for achieving 100\% from renewable energy sources in Islands. Int. J. Electr. Power Energy Syst. 2013b, 46, 198-210. [CrossRef]

47. Tzamalis, G.; Zoulias, E.; Stamatakis, M.; Varkaraki, E.; Lois, E.; Zannikos, F. Techno-economic analysis of an autonomous power system integrating hydrogen technology as energy storage medium. Renew. Energy 2011, 36, 118-124. [CrossRef]

48. Sakellaridis, N.; Mantzaris, J.; Tsourakis, Y.; Vournas, C. Operation and security assessment of the power system of Crete with integration of pumped storage and concentrated solar thermal plants. In Proceedings of Bulk Power System Dynamics and Control-IX Optimization, Security and Control of the Emerging Power Grid (IREP), 2013 IREP Symposium, Rethymno, Greece, 25-30 August 2013.

49. RSA, 2012. Operational Program of the South Aegean Region-Strategic Planning. Region of South Aegean, Athens, Greece. Available online: http://www.ceer.eu/portal/page/portal/EER_HOME/EER_ WORKSHOP/CEER-ERGEG\%20EVENTS/Electricity/WS-04_ELECTRICITY\%20INFRASTRUCTURE/ Tab1/HTSO.ppt (accessed on 14 July 2016). 
50. Tourism-SFSPSD, 2009. Special Framework for Spatial Planning and Sustainable Development of Tourism. Ministry of Energy, Environment and Climate Change, Athens, Greece. Available online: http://www. ypeka.gr /LinkClick.aspx?fileticket=v1z2MuVqGmE\%3d\&tabid=513 (accessed on 14 July 2016).

51. HEDNO. Installed Power in the Dodecanese. Unpublished work. 2015.

52. HSA. Annual Energy consumption of the Dodecanese Islands for the years 1993-2012. Unpublished work. 2015.

53. Tegou, L.; Polatidis, H.; Haralambopoulos, D. Environmental management framework for wind farm siting: Methodology and case study. J. Environ. Manage. 2010, 91, 2134-2147. [CrossRef] [PubMed]

54. HAS. Demographics, Spatial and economic data for the Dodecanese Islands. Unpublished work. 2015.

55. HSA. Capacity of Hotel-Type Accommodation and Camping Sites and Bed Occupancy for the Year 2012. Available online: http://www.statistics.gr/portal/page/portal/ESYE/PAGE-themes?p_param=A2001\& r_param=STO12\&y_param=2012_00\&mytabs=0 (accessed on 10 December 2014).

56. CICD. Shops, industrial units/crafts and mines Dodecanese for the year 2012. Unpublished work. 2015.

57. Corine Land Cover 2000. Available online: http://www.eea.europa.eu/data-and-maps/data/corine-landcover-2000-clc2000-seamless-vector-database (accessed on 1 Jeanery 2002).

58. Open Government Data. Cities, Towns and Villages of Greece. Available online: http://geodata.gov.gr/ geodata/ (accessed on 16 November 2014).

59. CRES, 2001. Thematic Map for the Estimation of the Technically and Economically Exploitable Potential of Wind Energy in the Dodecanese Islands. Center for Renewable Energy Sources and Saving. Available online: http:/ / www.cres.gr/kape/datainfo/maps.htm (accessed on 12 February 2014).

60. Oikonomou, E.; Kilias, V.; Goumas, A.; Rigopoulos, A.; Karakatsani, E.; Damasiotis, M.; Papastefanakis, D.; Marini, N. Renewable energy sources (RES) projects and their barriers on a regional scale: The case study of wind parks in the Dodecanese islands, Greece. Energy Policy 2009, 37, 4874-4883. [CrossRef]

61. Katsaprakakis, D.; Christakis, D.; Pavlopoylos, K.; Stamataki, S.; Dimitrelou, I.; Stefanakis, I.; Spanos, P. Introduction of a wind powered pumped storage system in the isolated insular power system of Karpathos-Kasos. Appl. Energy 2012, 97, 38-48. [CrossRef]

62. Katsaprakakis, D.; Christakis, D. Seawater pumped storage systems and offshore parks in islands with low onshore wind potential: A fundamental case study. Energy 2014, 66, 470-486. [CrossRef]

(C) 2016 by the authors; licensee MDPI, Basel, Switzerland. This article is an open access article distributed under the terms and conditions of the Creative Commons Attribution (CC-BY) license (http://creativecommons.org/licenses/by/4.0/). 